\title{
BMJ Open Injury epidemiology of workers by age, sex and industrial classification using the medical claim data of National Health Insurance in South Korea, 2012- 2015: a population-based retrospective study
}

\author{
Sung-Shil Lim, ${ }^{1,2,3}$ Jihyun Kim, ${ }^{1,2,3}$ Jong-Uk Won, ${ }^{1,2,3,4}$ Wanhyung Lee, ${ }^{5}$ \\ Yangwook Kim, ${ }^{3}$ Jin-Ha Yoon ${ }^{\circ}$ 1,2,3,4
}

To cite: Lim S-S, Kim J, Won J-U, et al. Injury epidemiology of workers by age, sex and industrial classification using the medical claim data of National Health Insurance in South Korea, 2012-2015: a population-based retrospective study. BMJ Open 2019;9:e029413. doi:10.1136/ bmjopen-2019-029413

- Prepublication history and additional material for this paper are available online. To view, please visit the journal (http:// dx.doi.org/10.1136/bmjopen2019-029413).

Received 25 January 2019 Revised 01 August 2019 Accepted 20 August 2019
Check for updates

(c) Author(s) (or their employer(s)) 2019. Re-use permitted under CC BY-NC. No commercial re-use. See rights and permissions. Published by BMJ.

For numbered affiliations see end of article.

Correspondence to Professor Jin-Ha Yoon; flyinyou@gmail.com

\section{ABSTRACT}

Objectives This study aimed to evaluate the risk of inpatient hospitalisation for all-cause injuries, according to age, sex and industrial classification (IC) in South Korea.

Design A population-based retrospective study. Setting and participants Data from the National Health Insurance Database on medical claims for the entire population of South Korean workers aged 25-59 years from January 2012 to December 2015 were retrieved. We observed 30900712 person-years $(63.1 \%)$ in male workers and 18105272 person-years (36.9\%) in female workers.

Main outcome measures The inpatient hospitalisation for all-cause injury was defined as admission for which the principal diagnosis included S00-T98 in the Korean version of International Classification of Diseases-10 codes.

Results $0 f 788575$ hospitalisations for all-cause injuries from 2012 to 2015, there were 565107 cases in male workers (1 828.8 per 100000 person-years) and 223468 cases in female workers (1 234.3 per 100 000 person-years). The top five ICs with hospitalisation rate ratios (HRR) for all-cause injuries in both sexes compared with the financial intermediation IC included agriculture, hunting and forestry (HRR $(95 \% \mathrm{Cl})$; male: 2.09 (1.98 to 2.20); female: 1.53 (1.40 to 1.67)); mining and quarrying (male: 2.05 (1.92 to 2.19 ); female: 1.54 (1.27 to 1.87)) and fishing (male: 1.68 (1.57 to 1.80); female: 1.71 (1.51 to 1.93)). A U-shaped relationship occurred between age and risk for injuries in males; however, only a linear relationship was shown in females, regardless of IC.

Conclusions The risk of injures varied by IC. The workers in agriculture, hunting, forestry, mining, quarrying and fishing were more vulnerable to injuries. The risk for injuries were higher among men and the age effect on this risk differed by sex. Thus, policy makers need to consider specific measures for prevention of injuries according to age, sex and IC.
Strengths and limitations of this study

- The study establishes the relationship between industrial classifications within which workers are employed and the risk for injuries among the entire insured population of employees aged 25-59 years, using data from the whole population database of the National Health Insurance in South Korea.

- The results of the study can inform the age and sex effects on injuries according to industrial classification in South Korea.

- Daily workers whose employment period is less than $<1$ month are not eligible for employee insured insurance; thus, such workers were excluded from our study.

\section{INTRODUCTION}

Injuries are major public health issues with considerable socioeconomic impact. In 2013, 973 million (uncertainty interval (UI) 942-993) and 4.8 million (UI 4.5-5.1) people sustained or died from injuries worldwide, respectively. ${ }^{1}$ Occupational injuries account for a considerable proportion of all-cause injuries, especially among the economically active population. Occupational risk factors, according to the WHO Comparative Risk Assessment project, were responsible for $8 \%$ of injuries in the year 2000. ${ }^{2}$ In South Korea, 89848 workers required 4 or more days of nursing due to occupational accidents among 18560142 workers eligible for occupational accidents compensation insurance in $2017 .^{3}$

In recent years, there has been an increasing amount of literature on age, service year and sex effects on injuries among workers. The risk for admission for fracture increases with age due to osteoporosis, loss of balance and 
decreased reaction time in elderly people. ${ }^{45}$ Associations between new employment and injuries among workers have been uncovered during decades of study in the US mining industry, ${ }^{6}$ and for those working as blue collars or apprentices in the non-agricultural private sector. ${ }^{7}$ With respect to the effect of sex on injuries, there were significant differences between both sexes in injuries related to motor vehicle trauma ${ }^{8}$ and to occupation. ${ }^{9}$

The risk of occupational injuries varies according to the industrial classification. Workers are exposed to their unique hazardous occupational environments depending on what industry type the workers belong to. According to the 2017 annual report of the Korea Occupational Safety and Health Agency (KOSHA), the incidence of industrial accidents per industry per 1000 persons were reported for mining and quarrying (16.94), forestry (1.36), fishing (1.12), construction (0.84), agriculture (0.73), manufacturing (0.61), transport (0.51), storage and communications and financial intermediation $(0.04) .{ }^{3}$ Given the sizeable socioeconomic costs of injuries among the economically active workers due to absence from work and loss of work capacity, it is necessary to estimate the risk for injuries according to age, sex and industrial classification to create policies to prevent injuries among targeted workers who are vulnerable to injury.

To date, there are few studies that have investigated the patterns of injury risk by age, sex and industry type in South Korea. To address these research gaps, we investigated the risk of inpatient hospitalisation for all-cause injuries identified by S00-T98 codes in the Korean version of International Classification of Diseases (ICD)-10 according to the industrial classification in which workers were employed, using the claim data of employees insured by the National Health Insurance (NHI) in South Korea. Furthermore, we assessed the effect of workers' age and sex on all-cause injuries among workers aged 25-60 years by industrial classification.

\section{METHODS}

\section{Overall design}

Data were retrieved from claim files of the NHI Database (NHID). The NHI system is a single insurer and provided universal coverage to approximately $98 \%$ of the population in the territory of Korea in $2014 .^{10}$ The medical billing and claims in NHID were reviewed by a quality assessment system conducted by the Korean Health Insurance Review and Assessment Service (HIRA). ${ }^{11}$ HIRA also reviewed whether treatment and examination by medical providers were performed properly at an appropriate level and cost. The insured population in South Korea are classified as employee insured, self-employed insured and medical aid beneficiaries. Employees insured include the workers (payer for insurance premium), the insured person's spouse, direct lineal ascendants, descendants and unmarried brothers or sisters. In this study, we included only workers, aged between 25 and 59 years, who pay for insurance premium, not their dependents.
Korea's retirement age is usually 60 years, and almost all men have compulsory military service for 2 years before 25 years. Of 51688103 person-years of workers in the NHI database from 2012 to 2015, 2682119 (646 629; 704 151; 637571 and 693768 in 2012, 2013, 2014 and 2015, respectively) person-years with missing or masked values of industrial classification were excluded. In all analyses, the numbers of person-years of follow-up were 11622 968, 12043 582, 12488898 and 12850536 person-years in 2012, 2013, 2014 and 2015, respectively.

\section{Industrial classification}

To classify the industries, the International Standard Industrial Classification of All Economic Activities (ISIC) was used in our study. The ISIC is used for reporting of statistics according to such industry types internationally to compare statistical data on economic activities. ISIC was first introduced in 1948 by the United Nations and revised periodically. ${ }^{12}$ The NHID adopted and has continued to use the previous ISIC Revision (Rev) 3.0. ${ }^{13}$ The financial officer of each company where the insured employees work reports the industrial classification of their company to the NHI according to ISIC Rev 3.0. NHID contains the general information, including sex, age (5-year categories), socioeconomic characteristics and industrial classification, if the insured people work. It represents the characteristics of the insured person on January 1 of each year. In our study, the industrial classification of employees was categorised as level 1 of ISIC Rev 3.0 (online supplementary table 1-1). It was assumed that the employee had worked for 1 year (one personyear) at each level 1 of industry classification in which the employee was employed on January 1 of each year.

\section{Cases included}

All NHI-insured claims requiring inpatient hospitalisation were identified for calendar years from 1 January 2012 to 31 December 2015. Hospitalisation for injury, poisoning and certain other consequences of external causes (from this point forward called 'all-cause injury') was defined as any kind of admission with principal diagnosis in S00T98 using the Korean Standard Classification of Diseases (KCD)-7 codes. The KCD-7 code is the Korean version of ICD-10, a medical classification list by WHO. The KCD-7 codes were selected as the principal diagnosis in each hospitalisation which were most demanding and used frequently for treatment and medical examination. The cases included all admissions which covered inpatient, emergency department admissions or short stay, for which healthcare institutions claimed medical expenses in NHI. We included all-cause injuries regardless of whether the injury occurred at the workplace or not.

\section{Statistical analysis}

In the descriptive analyses (table 1), we presented categorical variables as numbers and percentages by year. Hospitalisation rates were calculated as total counts of hospitalisation divided by person-years according to the 
Table 1 Descriptive statistics of the study population by study variables from 2012 to 2015

\begin{tabular}{|c|c|c|c|c|c|c|c|c|}
\hline \multirow[t]{3}{*}{ Year } & \multirow{2}{*}{\multicolumn{2}{|c|}{$\begin{array}{l}2012 \\
\mathrm{~N}=11622968\end{array}$}} & \multirow{2}{*}{\multicolumn{2}{|c|}{$\begin{array}{l}2013 \\
N=12043582\end{array}$}} & \multirow{2}{*}{\multicolumn{2}{|c|}{$\begin{array}{l}2014 \\
\mathrm{~N}=12488898\end{array}$}} & \multirow{2}{*}{\multicolumn{2}{|c|}{$\begin{array}{l}2015 \\
N=12850536\end{array}$}} \\
\hline & & & & & & & & \\
\hline & $\mathbf{N}$ & $\%$ & $\mathbf{N}$ & $\%$ & $\mathbf{N}$ & $\%$ & $\mathbf{N}$ & $\%$ \\
\hline \multicolumn{9}{|l|}{ Sex } \\
\hline Male & 7457478 & 64.2 & 7627463 & 63.3 & 7837976 & 62.8 & 7977795 & 62.1 \\
\hline Female & 4165490 & 35.8 & 4416119 & 36.7 & 4650922 & 37.2 & 4872741 & 37.9 \\
\hline \multicolumn{9}{|l|}{ Age (years) } \\
\hline 25-29 & 1822264 & 15.7 & 1746312 & 14.5 & 1704165 & 13.6 & 1719966 & 13.4 \\
\hline $30-34$ & 2063733 & 17.8 & 2146211 & 17.8 & 2209712 & 17.7 & 2176135 & 16.9 \\
\hline 35-39 & 1933267 & 16.6 & 1951552 & 16.2 & 1939308 & 15.5 & 1989535 & 15.5 \\
\hline $40-44$ & 1941678 & 16.7 & 2040123 & 16.9 & 2103874 & 16.9 & 2143306 & 16.7 \\
\hline $45-49$ & 1611830 & 13.9 & 1688018 & 14.0 & 1829624 & 14.6 & 1936629 & 15.1 \\
\hline $50-54$ & 1398268 & 12.0 & 1517161 & 12.6 & 1611516 & 12.9 & 1678789 & 13.1 \\
\hline 55-59 & 851928 & 7.3 & 954205 & 7.9 & 1090699 & 8.7 & 1206176 & 9.4 \\
\hline \multicolumn{9}{|l|}{ Industrial classification } \\
\hline $\begin{array}{l}\text { A-agriculture, hunting and } \\
\text { forestry }\end{array}$ & 29025 & 0.2 & 31867 & 0.3 & 34672 & 0.3 & 35856 & 0.3 \\
\hline B-fishing & 16636 & 0.1 & 17269 & 0.1 & 18200 & 0.1 & 18661 & 0.1 \\
\hline $\mathrm{C}-$ mining and quarrying & 14719 & 0.1 & 14091 & 0.1 & 13817 & 0.1 & 13638 & 0.1 \\
\hline D-manufacturing & 3376353 & 29.1 & 3475266 & 28.9 & 3601200 & 28.8 & 3674502 & 28.6 \\
\hline $\begin{array}{l}\text { E-electricity, gas and water } \\
\text { supply }\end{array}$ & 84675 & 0.7 & 84845 & 0.7 & 86037 & 0.7 & 86805 & 0.7 \\
\hline $\mathrm{F}-$ construction & 725944 & 6.2 & 741270 & 6.2 & 769337 & 6.2 & 772942 & 6.0 \\
\hline $\begin{array}{l}\text { G-wholesale and retail trade; } \\
\text { repair of motor vehicles, } \\
\text { motorcycles and personal and } \\
\text { household goods }\end{array}$ & 1274723 & 11.0 & 1348498 & 11.2 & 1443257 & 11.6 & 1530854 & 11.9 \\
\hline $\mathrm{H}-$ hotels and restaurants & 243847 & 2.1 & 280340 & 2.3 & 328634 & 2.6 & 371440 & 2.9 \\
\hline $\begin{array}{l}\text { I-transport, storage and } \\
\text { communications }\end{array}$ & 595282 & 5.1 & 596427 & 5.0 & 595943 & 4.8 & 583706 & 4.5 \\
\hline $\mathrm{J}$-financial intermediation & 419139 & 3.6 & 429673 & 3.6 & 434251 & 3.5 & 432922 & 3.4 \\
\hline $\begin{array}{l}\text { K-real estate, renting and } \\
\text { business activities }\end{array}$ & 1460983 & 12.6 & 1514924 & 12.6 & 1546239 & 12.4 & 1588618 & 12.4 \\
\hline $\begin{array}{l}\text { L-public administration and } \\
\text { defence; compulsory social } \\
\text { security }\end{array}$ & 844684 & 7.3 & 850709 & 7.1 & 868755 & 7.0 & 879361 & 6.8 \\
\hline M-education & 996031 & 8.6 & 1036310 & 8.6 & 1041092 & 8.3 & 1068274 & 8.3 \\
\hline $\mathrm{N}-$ health and social work & 823269 & 7.1 & 876642 & 7.3 & 929764 & 7.4 & 985660 & 7.7 \\
\hline $\begin{array}{l}\text { O-other community, social and } \\
\text { personal service activities }\end{array}$ & 677336 & 5.8 & 706829 & 5.9 & 739919 & 5.9 & 770718 & 6.0 \\
\hline $\begin{array}{l}\text { P-private households with } \\
\text { employed persons }\end{array}$ & 27164 & 0.2 & 25627 & 0.2 & 25023 & 0.2 & 24037 & 0.2 \\
\hline $\begin{array}{l}\text { Q-extraterritorial organisations } \\
\text { and bodies }\end{array}$ & 13158 & 0.1 & 12995 & 0.1 & 12758 & 0.1 & 12542 & 0.1 \\
\hline
\end{tabular}

sex, age group, year and industrial classification. The direct method of standardisation of hospitalisation rate was used to adjust for age and sex. For reference, we adjusted the rate to the population of insured employees reported by NHI in $2015^{13}$ (25-29 years, 1732 065; 30-34 years, 2151 548; 35-39 years, 2119 908; 40-44 years, 2222 646; 45-49 years, 2115 189; 50-54 years, 1801657 and 55-59 years, 1401 291). We also used Poisson regression, correcting for the ratio of the deviance and the $\mathrm{df}$ of 1 , due to the presence of an overdispersed response variable. ${ }^{14}$ 
Furthermore, we used the logarithm of the person-years at risk as the offset to estimate the hospitalisation rate ratio (HRR) for the association between workers' industrial classification and injuries. To establish the effect of age on all-cause injury, we calculated the HRR of workers in each industrial classification, compared with those aged 25-29 years in the financial intermediation industry, by sex. All analyses and all graphical descriptions were conducted using SAS V.9.4 (SAS Institute, Cary, North Carolina, USA) and R V.3.4.4 (R Foundation for Statistical Computing, Vienna, Austria).

\section{Patient and public involvement statement}

We used administrative claim data and did not involve patients in this study.

\section{RESULTS}

Table 1 shows the yearly characteristics of the population. Of 49005984 person-years from 2012 to 2015, there were 30900712 person-years $(63.1 \%)$ from male workers and 18105272 person-years $(36.9 \%)$ from female workers. The top five proportions of level 1 industry classifications in which workers were employed from 2012 to 2015 were $28.8 \%$ in manufacturing (14 127321 person-years); $12.5 \%$ in real estate, renting and business activities (6 110764 person-years); $11.4 \%$ in wholesale and retail trade, repair of motor vehicles, motorcycles and personal and household goods (5 597332 person-years); $8.5 \%$ in education (4 141707 person-years) and $7.4 \%$ in health and social work (3 615335 person-years).

Of 788575 injuries from 2012 to 2015, inpatient hospitalisations for dislocations, sprains and strains of specified and multiple body regions (254 039 cases; $32.2 \%$ ) were the most common, followed by fractures of other limbs (203 020 cases; $25.8 \%$ ), and other injuries of specified, unspecified and multiple body regions (152 098 cases; 19.3\%; see online supplementary tables 1-2). Between 2012 and 2015, there were 565107 all-cause injuries in male workers during 30900712 person-years (1 828.8 per 100000 person-years) and 223468 injuries in female workers during 18105272 person-years (1 234.3 per 100 000 person-years). Figure 1 shows the crude and standardised rates for hospitalisation in insured employees from 2012 to 2015. The hospitalisation rates were standardised using the number of insured employees reported by NHI in 2015 . The crude rate per 100000 person-years ranged from 1187.3 in male workers in the financial intermediation industry in 2012 to 2773.3 in agriculture, hunting and forestry in 2013. Among the female workers, this ranged from 690.8 in the financial intermediation industry in 2012 to 2104.0 in fishing in 2015. The standardised rate per 100000 person-years ranged between 1204.5 in male workers in the financial intermediation industry in 2012 and 2758.9 in agriculture, hunting and forestry in 2013. In females, there were 765.8 in extraterritorial organisations and bodies in 2012 and 2104.7 in mining and quarrying in 2014.
Table 2 shows the number, hospitalisation rate and adjusted HRR of all-cause injuries by sex. The top five industrial classifications by year-adjusted and age-adjusted HRR in male workers compared with financial intermediation were agriculture, hunting and forestry $(\mathrm{HRR}=2.09$; $95 \%$ CI 1.98 to 2.20); mining and quarrying (HRR=2.05; 95\% CI 1.92 to 2.19$)$; construction (HRR $=1.74 ; 95 \% \mathrm{CI}$ 1.68 to 1.81 ); fishing ( $\mathrm{HRR}=1.68$; $95 \%$ CI 1.57 to 1.80 ) and transport, storage and communications (HRR $=1.62$; $95 \%$ CI 1.56 to 1.68 ). With respect to female workers, the corresponding top five HRRs compared with financial intermediation were fishing (HRR $=1.71 ; 95 \%$ CI 1.51 to 1.93); mining and quarrying ( $\mathrm{HRR}=1.54 ; 95 \% \mathrm{CI} 1.27$ to 1.87); agriculture, hunting and forestry ( $\mathrm{HRR}=1.53$; $95 \%$ CI 1.40 to 1.67$)$; health and social work (HRR $=1.52$; $95 \% \mathrm{CI} 1.46$ to 1.58$)$; and hotels and restaurants (HRR $=1.47 ; 95 \%$ CI 1.40 to 1.54$)$.

There was a stronger positive trend between age and all-cause injuries in female workers than in male workers (figure 2). In males, however, a U-shaped relationship was shown between age and hospitalisation for all-cause injuries. The HRRs for all-cause injuries in female workers compared with female workers aged 25-29 years were 0.94 (95\% CI 0.91 to 0.96 ) for ages $30-34,1.05$ (95\% CI 1.02 to 1.08 ) for ages $35-39,1.27$ (95\% CI 1.23 to 1.30 ) for ages $40-44,1.82$ (95\% CI 1.77 to 1.87 ) for ages $45-59$, $2.72(95 \%$ CI 2.64 to 2.80$)$ for ages 50-54, 3.11 (95\% CI 3.02 to 3.20) for ages 55-59. The HRRs for all-cause injuries of male workers compared with male workers aged 25-29 years were 0.90 (95\% CI 0.87 to 0.92$)$ for ages $30-34,0.87$ (95\% CI 0.85 to 0.90 ) for ages $35-39,0.86$ (95\% CI 0.84 to 0.89 ) for ages $40-44,0.91$ (95\% CI 0.88 to 0.93 ) for ages $45-59,0.97$ (95\% CI 0.94 to 1.00 ) for ages $50-54$ and 1.01 (95\% CI 0.98 to 1.04 ) for ages 55-59 years. Figure 3 shows the adjusted HRR and $95 \% \mathrm{CI}$ of all-cause injuries referenced to the 25-29 years of age male and female financial intermediation strata, respectively. A graphical representation of these findings shows the strong linear relationship of all-cause injuries with age in female workers and the U-shaped relationship in male workers, regardless of industrial classification, except agriculture, hunting and forestry; fishing; mining and extraterritorial bodies.

\section{DISCUSSION}

In this study based on the population-based claim data of NHI among employees aged 25-59 years employees, we evaluated the relationship between industrial classifications and risk of inpatient hospitalisations for injury, poisoning and certain other consequences of external causes. The top five industries with risk of hospitalisation for all-cause injuries for both sexes included agriculture, hunting and forestry (item code of ISIC: A); fishing (B) and mining and quarrying $(\mathrm{C})$. Other industries among these top five were construction (F), and transport, storage and communications (I) in male employees; and hotels and restaurants $(\mathrm{H})$, and health and social work 


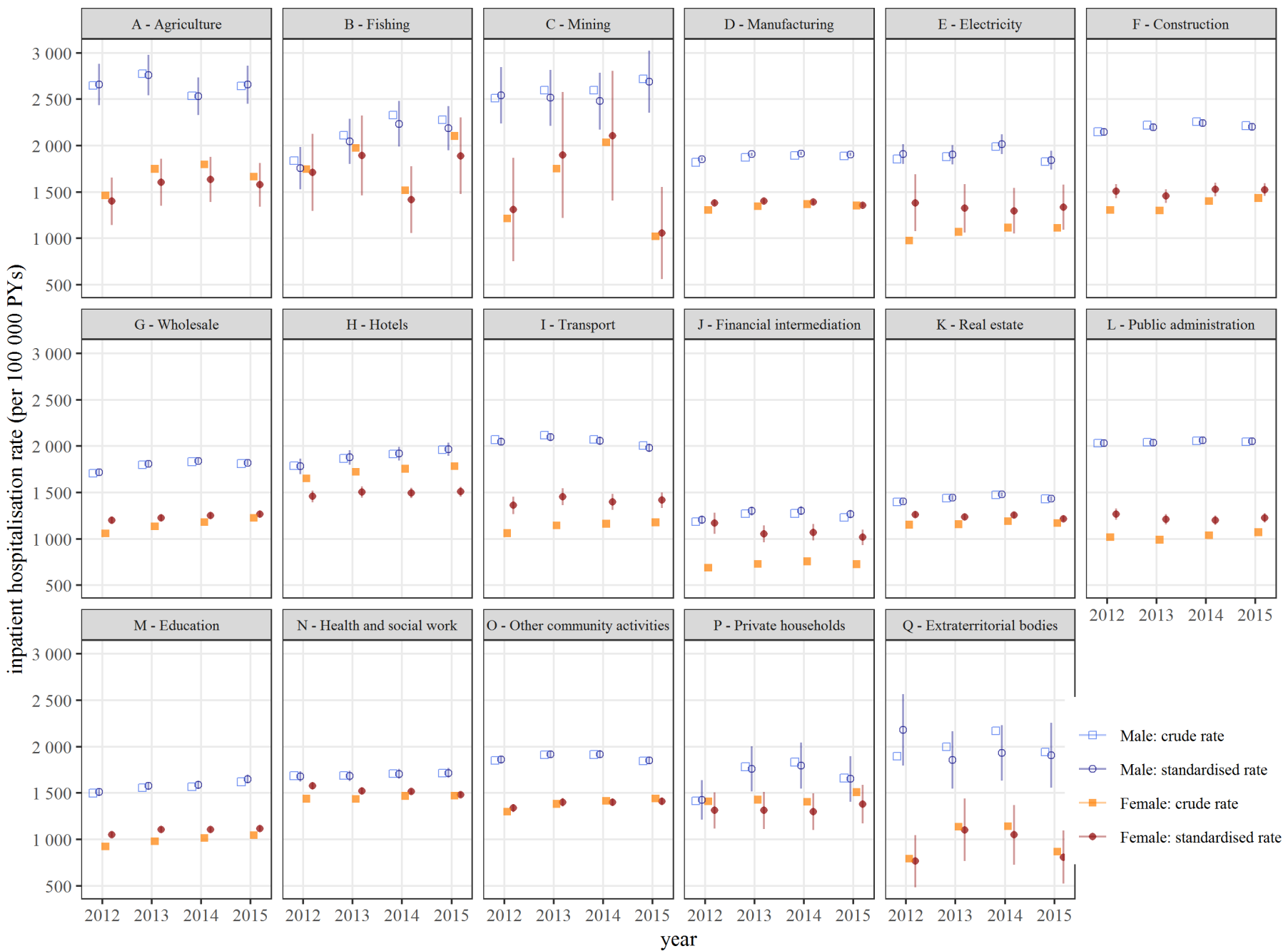

Figure 1 The crude, standardised rate per 100000 person-years (PYs) and 95\% Cl of inpatient hospitalisation for all-cause injuries according to the industrial classification for workers aged 25-59 years in South Korea, 2012-2015. The standardised rate of hospitalisation for injury, poisoning and certain other consequences of external causes (S00-T98) was referenced for the population of insured employees reported by the National Health Insurance in 2015 (25-29 years of age, 1 732 065; 30-34 years of age, 2 151 548; 35-39 years of age, 2119 908; 40-44 years of age, 2222 646; 45-49 years of age, 2115 189; 50-54 years of age, 1801657 and 55-59 years of age, 1401 291). The industrial classification titles in the grey box of the figure are not the full names of the level 1 International Standard Industrial Classification of All Economic Activities (full names are shown in the online supplementary table 1-1).

(N) in female employees. These results were consistent with the 2017 Annual Survey of Occupational Injuries and Illnesses in the USA ${ }^{15}$ which showed that agriculture, forestry, fishing and hunting (5.0 per 100 full-time equivalent workers) had the highest incidence of occupational injuries. It was also consistent with the 2017 KOSHA annual report, which showed that the top five industries with the highest incidence were mining and quarrying; forestry, fishing, construction, and agriculture. ${ }^{3}$

It is well established from previous studies that workers in agriculture, hunting and forestry, mining and quarrying and fishing are exposed to a hazardous occupational environment and are vulnerable to injuries. In a study among male workers in agriculture born between 1933 and 1977 in England and Wales, 3238 (30\%) of 10 765 participants reported at least one occupational accident from age 14 to 64 years, mainly due to handling, lifting or carrying (4.9/1000 person-years), falls from a height (4.6/1000 person-years) or injury by animals (3.4/1000 person-years).${ }^{16}$ Historically, mines are considered the most hazardous work environments worldwide. In a cohort study of 56576 male workers in the nickel industry employed for a cumulative minimum of 6 months in southern Ontario, Canada, the workers in mining had a higher risk of injury and death than the general population in the Province of Ontario (standardised mortality ratio $=162 ; 95 \%$ CI 153 to 171$).{ }^{17}$ High non-fatal and fatal injuries in miners were partly attributable to handling of non-powered hand tools and carrying heavy materials (eg, off-road ore haulage). ${ }^{18}$ With fishing, a retrospective study of 440355 fishermen-years at risk based on official mortality files in Great Britain revealed that the fatal accident rate was 103.1 per 100000 fishermen-years from 1976 to 1995 . This was 52.4 times higher (95\% CI 42.9 to 


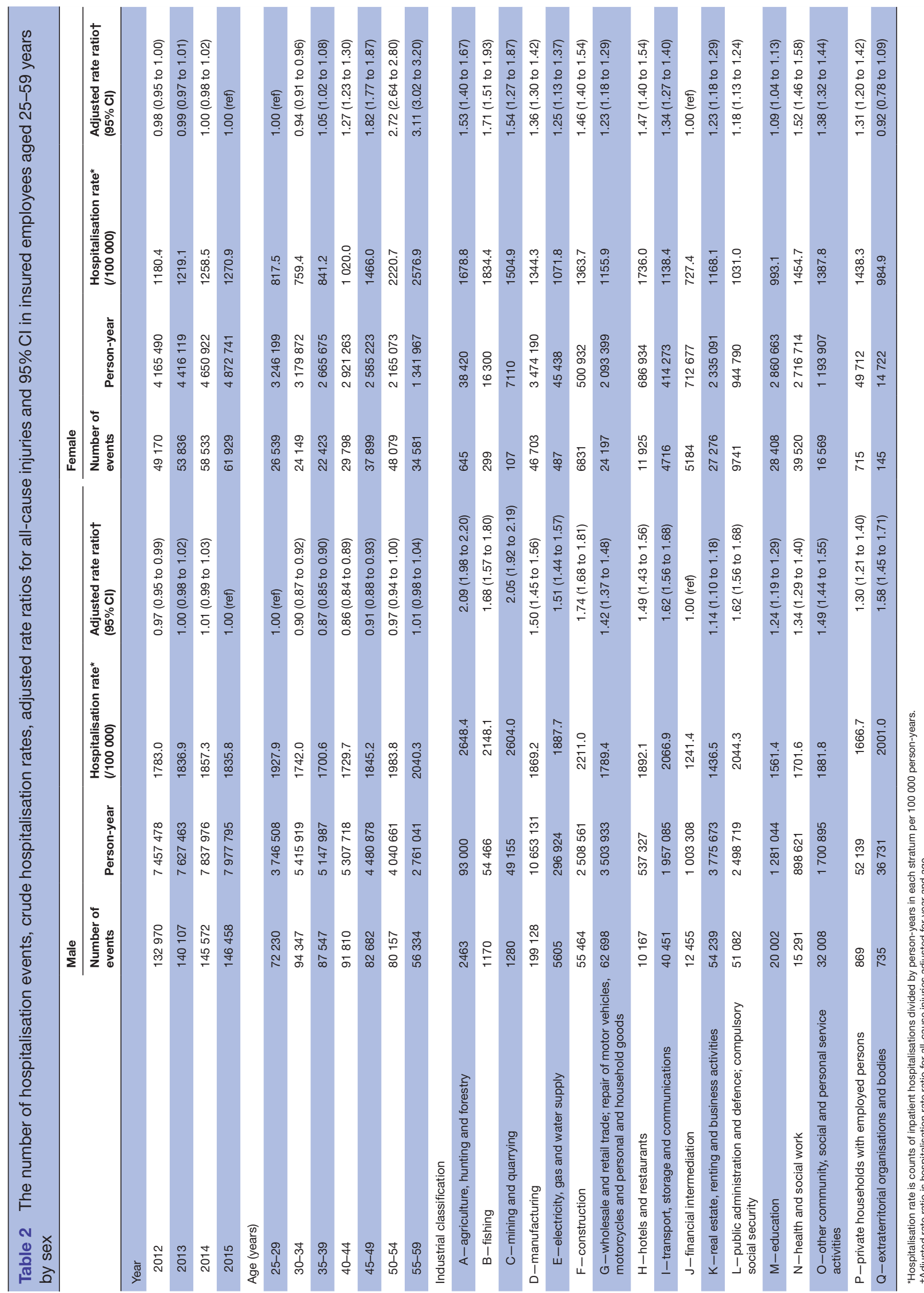



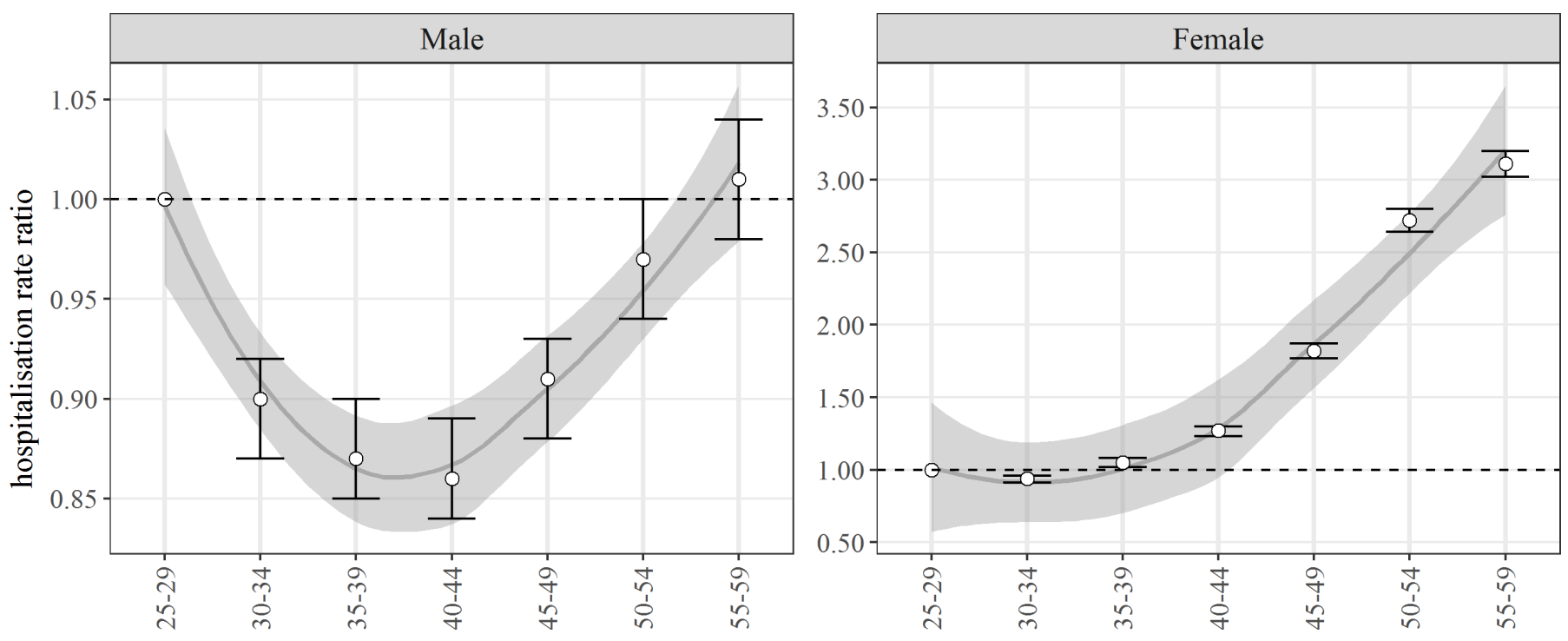

age

Figure 2 The adjusted hospitalisation rate ratios (HRR), 95\% Cl of hospitalisation for all-cause injuries and trends for workers aged 25-59 years in South Korea, 2012-2015. The age and year adjusted HRR for each stratum was compared with those of the employees aged 25-29 years, by sex, respectively. The dark grey line indicates the smooth non-parametric curve using a loess smoother (the loess span 1.00) and the grey shadow indicates the $95 \% \mathrm{Cl}$ of smooth curve.

63.8) than all workers in Great Britain during the same period. ${ }^{19}$ A study on the work-related injuries admitted to hospitals in New Zealand's Midland Trauma System from 2012 to 2015 revealed that workers in agriculture/ forestry/fishing had the highest risk for injuries among industrial types (agriculture/forestry/fishing 564.5 per 100000 workers; manufacturing: 426.3 per 100000 workers; transport/postal/warehousing: 294.9 per 100 000 workers; construction: 275.5 per 100000 workers).$^{20}$

One interesting finding in our study was the sex-associated difference in age trend in terms of the risk of injuries. A U-shaped relationship was found between age and risk for injuries in males aged 25-59 years and a linear relationship was found in females aged 30-59 years (regardless of industrial classification). Two factors a) protective effects from long period of employment and b) the harmful effects from increased age on the risk of injuries could explain these relationships. With respect to the protective effect from a long career, a number of studies have postulated that injuries occur more frequently in people with shorter career experiences. ${ }^{1821}$ Temporary workers showed a rate ratio of 2.94 (95\% CI 2.40 to 3.61$)$ for non-fatal occupational injuries and 2.54 (95\% CI 1.88 to 3.42) for fatal occupational injuries compared with permanent workers, which might be mediated through length of employment. ${ }^{21}$ However, in our study, the age effects surpassed the protective effect from career experiences, with better knowledge of work and experience, in males aged 55-59 years and females aged 35-39 years. It is now well established from a variety of studies that the risk of fracture increases with age. In a study based on a population of about 42 million people in Kanto, Japan, the annual rate per 1000 personyears was 1.29 among those aged 20-39 years, 2.13 among those aged 40-64 years and 5.22 among those aged 65-79 years. $^{22}$ The risk of fracture in the older age groups was greater in females than in males (male, 40-64 years, 2.06; 65-79 years, 2.93; females, 40-64 years, 2.19; 65-79 years, 7.28). ${ }^{22}$ The risk of osteoporosis increases with age, resulting in an increase of hospitalisation from injuries due to susceptibility to fracture. ${ }^{4}$ Especially for women, menopause increases fracture risk in old workers. Menopause results in an oestrogen decrease, which functions as a key regulator of skeletal growth and maturation through decrease in osteoclast formation and activity and increase in osteoblast formation, differentiation and proliferation. ${ }^{23}$ In the Women's Health Initiative Clinical Trial cohort, women younger than 40 years at menopause had a higher risk of any fracture than women who were aged $\geq 50$ years at menopause (HR 1.36; 95\% CI 1.11 to 1.67$).{ }^{24}$ In addition, loss of balance, weak muscle strength and decreased reaction time also increases the risk of hospitalisation due to injuries in older workers. ${ }^{5}$ Another possible explanation of age effects on injuries is the effect of gender norms in South Korea. A break in a women's career due to pregnancy and childbirth might induce the lack of protective effects from career experiences in women of childbearing age. In Korean culture where mothers' and wives' roles have been preserved as the fundamental duty of women, although weakened nowadays, career interruptions due to child care occurs mainly among women. ${ }^{25}$ This career break and re-employment in unfamiliar occupations could increase the risk of injury for women. These gender (cultural roles) and sex (biological) differences support our current results.

We used the medical claim data of NHI, instead of data on worker's compensation insurance, which is known to be a better representation of occupational injuries. However, the workers' industrial accident compensation database might not include all occupational injuries in 

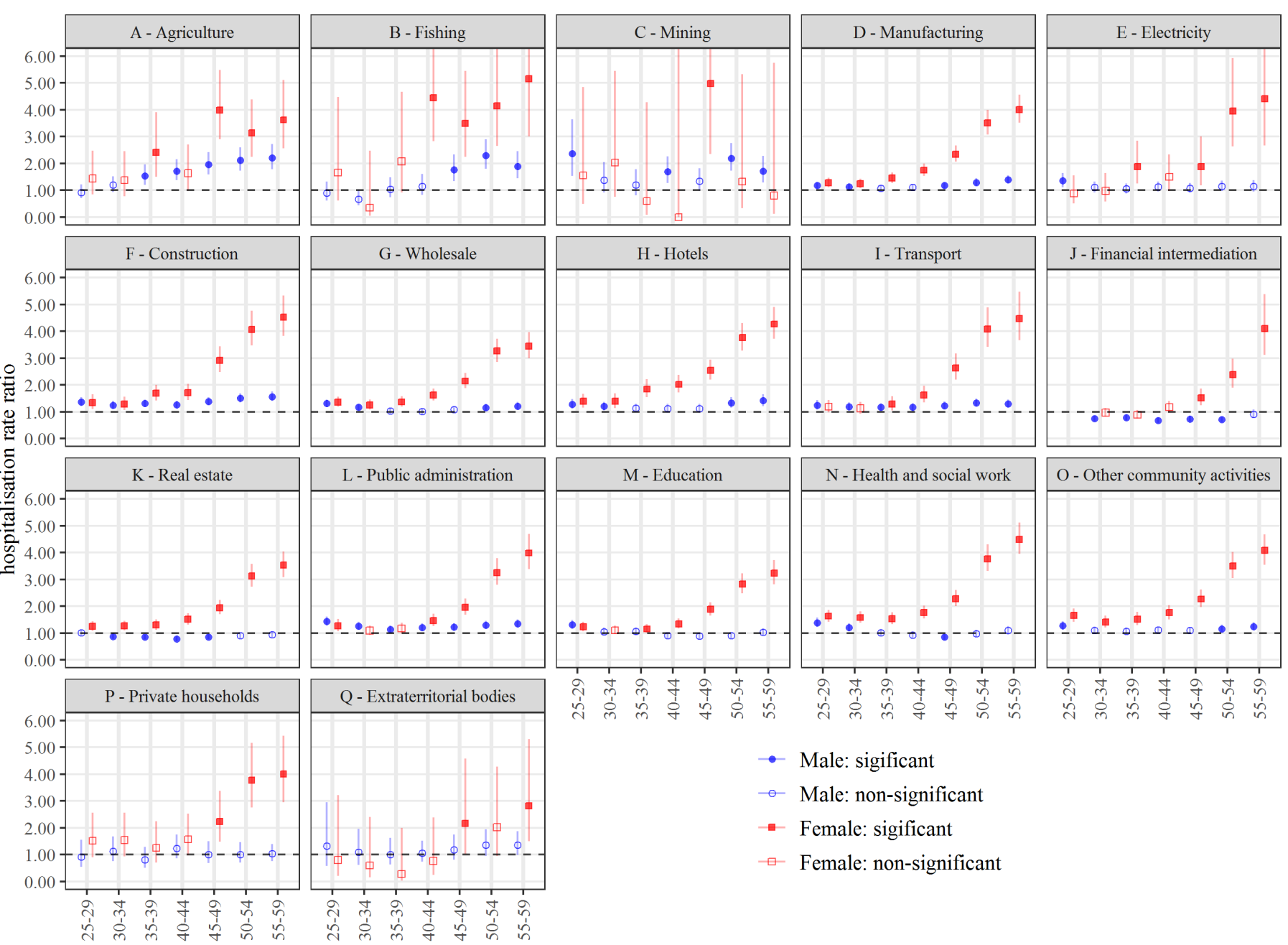

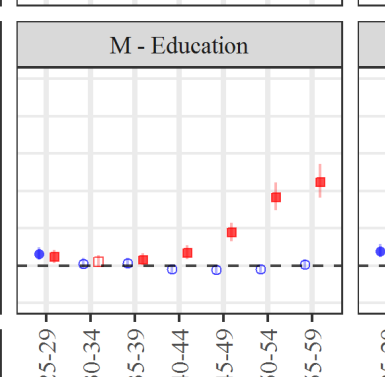

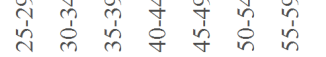

- Male: sigificant

- Male: non-significant

- Female: sigificant

$\square$ Female: non-significant

Figure 3 The year-adjusted and age-adjusted hospitalisation rate ratio (HRR) and 95\% $\mathrm{Cl}$ of hospitalisations for all-cause injuries according to industrial classification, 2012-2015. The age-adjusted and year-adjusted HRR for each stratum was compared with that of the employees aged 25-29 years insured in the financial intermediation, by sex, respectively; The industrial classification titles in the grey box of figure are not the full names of the level 1 International Standard Industrial Classification of All Economic Activities (the full names are shown in online supplementary table 1-1).

South Korea. KOSHA has only reported occupational injuries requiring $>3$ days of medical treatment and that are eligible for compensation benefits. ${ }^{3}$ Thus, injuries requiring $\leq 3$ days of medical treatment are not reported. Furthermore, the employers are not obliged to report the occupational injuries to authorities if the cost of the worker's injury is paid directly by employer up until 2014 when a law on employer reporting of industrial accidents was put into place. Previous ecological studies among countries revealed that there may be under-reporting of occupational injuries, especially non-fatal occupational injuries. ${ }^{26}{ }^{27}$ In addition, injuries caused by commuting accidents and injuries in daily life by job-related lifestyle behaviours, fatigue or psychological and physical problems were not reported in the database of worker's compensation insurance, although these injuries resulted from indirect effects of workers' jobs. In the GAZ and ELectricité(GAZEL) cohort which included 20625 workers over a 12-year period (1989-2001), self-reported work fatigue was associated with at-work crashes in both sexes of workers and crashes while commuting among female workers. ${ }^{28}$

To our knowledge, this is the first study to establish the relationship between age, sex and industrial classifications in which workers are employed and the risk of hospitalisation for injuries, using data from the whole population database of NHI in South Korea. We conducted our analysis using qualified data from NHID. The NHI system is a single insurer in South Korea and is reviewed by a quality assessment system in HIRA. ${ }^{11}$ HIRA, a government-affiliated quality assessment agency, reviewed all the medical claims provided in the NHI system. However, our results should be interpreted within the context of the study's limitations. First, the injuries reported in our study included occupational injuries and leisure-time injuries. We assumed that leisure-time injuries were not significantly different across the industrial type. Nevertheless, the differences in the non-work exposures may explain the differences observed in our study. However, the average working time of Korean workers is longer than 
in other Organisation for Economic Co-operation and Development (OECD) countries. Average annual hours worked was 2084 hours in South Korea and 1751 hours in OECD countries in $2015 .^{29}$ Therefore, it is likely that the proportion of injuries might be more related to occupation in South Korea than in other countries. By studying all the injuries of workers regardless of the cause, the results of our research might contain the indirect effect of occupation such as traffic accidents or accidents due to carelessness caused by fatigue or physical and mental problems, or job-related lifestyle behaviours resulting from the workplace. Second, workplace industry classification in which employees are employed is categorised by the financial officers of each company. In addition, daily workers whose employment period is $<1$ month are not eligible for employee insured insurance, resulting in the exclusion of these workers from our study. However, the number of permanent employees in labour force survey of the Ministry of Labor ${ }^{30}$ was not much different from the number of insured employees according to the industrial classification of this study in 2015 (mining and quarrying: 13282 (labour force survey) vs 13638 (NHI); manufacturing: 3453127 vs 3674 502; construction: 810 210 vs 772 942; financial intermediation: 446765 vs 432 922; others are shown in online supplementary tables 1-3). Third, it is assumed that a worker worked for 1 year in the industrial classification based on their employment on January 1 of each year. However, workers in vulnerable occupations such as temporary/daily employees might not have worked for 1 year, and are likely to change jobs. In addition, deceased workers in each year could not have completed 1 year of employment, although the mortality rate under 59 years is not high. These limitations might lead to biassed results in our study, but the exclusion of vulnerable employment in industrial classification might result in underestimation of the risk of injuries in industrial classification characterised by high proportions of vulnerable employment. Fourth, identification of injuries based on the KCD-7 in the NHI database might induce outcome misclassification. With respect to outpatient hypertension diagnoses, medical claim data have a low sensitivity $(43 \%)$ and relatively high specificity $(61 \%){ }^{31}$ Although the method of outcome selection using claim data for inpatient visits in our study could bring about accuracy of validated outcome, this misclassification of an outcome might still exist, resulting in biassed results. Fifth, we excluded the young adults aged under 25 years because almost all Korean men aged 20-22 years join the army and perform military service for about 2 years. This exclusion might underestimate the age effects on injuries among young adults. Sixth, because of the limitation of the NHI database, it was not possible to identify important occupational factors, such as the years of employment, shift work and overtime which are associated with risk of injuries. ${ }^{32}$ Additional longitudinal studies based on the NHI database, with the data from the labour survey or industrial compensation data are needed to establish the risk of injuries according to industrial classification.
In summary, we reported the risk of injuries according to the level 1 of ISIC using the large, nationwide representative data of NHI in South Korea from 2012 to 2015. In-depth analyses of sex and age stratification showed that effect of age on risk of injury differed by sex of worker. Policy makers need to establish a priority of injury prevention for industrial classification, characterised by vulnerability to injuries with consideration for the age and sex of workers.

\section{Author affiliations}

${ }^{1}$ The Institute for Occupational Health, Yonsei University College of Medicine, Seoul, Republic of Korea

${ }^{2}$ Department of Occupational and Environmental Medicine, Severance Hospital, Seoul, Republic of Korea

${ }^{3}$ Department of Public Health, Yonsei University, Seodaemun-gu, , Republic of Korea ${ }^{4}$ Department of Preventive Medicine, Yonsei University College of Medicine, Seoul, Republic of Korea

${ }^{5}$ Department of Occupational and Environmental Medicine, Gachon University Gil Medical Center, Incheon, Republic of Korea

Acknowledgements The authors would like to thank the government authorities of the Department of Big Data Steering, National Health Insurance Service. The authors would also like to thank all the scientists working in the National Health Insurance Service who collected and handled the data from medical claim data of the National Health Insurance.

Contributors S-SL and J-HY conceptualised and designed the study. S-SL, JK and WL performed the formal analysis. S-SL, JK, WL and YK wrote the original draft of the manuscript. J-HY devised and supervised the entire process. J-UW and WL validated the study. All of the authors read and approved the final manuscript.

Funding The authors have not declared a specific grant for this research from any funding agency in the public, commercial or not-for-profit sectors.

Competing interests None declared.

Patient consent for publication Not required.

Ethics approval This study was approved by the Institutional Review Board (IRB) of Severance Hospital, Seoul, South Korea (IRB approval number: Y-2017-0100). As this was a retrospective study, the IRB waived the requirement for informed consent.

Provenance and peer review Not commissioned; externally peer reviewed. Data availability statement Data are available on reasonable request.

Open access This is an open access article distributed in accordance with the Creative Commons Attribution Non Commercial (CC BY-NC 4.0) license, which permits others to distribute, remix, adapt, build upon this work non-commercially, and license their derivative works on different terms, provided the original work is properly cited, appropriate credit is given, any changes made indicated, and the use is non-commercial. See: http://creativecommons.org/licenses/by-nc/4.0/.

\section{REFERENCES}

1. Haagsma JA, Graetz N, Bolliger I, et al. The global burden of injury: incidence, mortality, disability-adjusted life years and time trends from the global burden of disease study 2013. Inj Prev 2016;22:3-18.

2. Fingerhut M, Nelson DI, Driscoll T, et al. The contribution of occupational risks to the global burden of disease: summary and next steps. Med Lav 2006;97:313-21.

3. Korea occupational safety and health agency (KOSHA). 2017 KOSHA annual report. Available: http://english.kosha.or.kr/english/content. do?menuld=12089 [Accessed 21 Dec 2018].

4. Anagnostis P, Karagiannis A, Kakafika Al, et al. Atherosclerosis and osteoporosis: age-dependent degenerative processes or related entities? Osteoporos Int 2009;20:197-207.

5. Davies JCet al. The rising number of underfoot accidents after the menopause causes both fractures and non-fracture injuries. QJM 2001;94:699-707.

6. Friedman LS, Almberg KS, Cohen RA. Injuries associated with long working hours among employees in the US mining industry: risk factors and adverse outcomes. Occup Environ Med 2019;76:389-95. 
7. Bena A, Giraudo M, Leombruni R, et al. Job tenure and work injuries: a multivariate analysis of the relation with previous experience and differences by age. BMC Public Health 2013;13:869.

8. Wang L, Ning P, Yin P, et al. Road traffic mortality in China: analysis of national surveillance data from 2006 to 2016. The Lancet Public Health 2019;4:e245-55.

9. Berecki-Gisolf J, Smith PM, Collie A, et al. Gender differences in occupational injury incidence. Am J Ind Med 2015;58:299-307.10.1002/ajim.22414

10. Kim JA, Yoon S, Kim LY, et al. Towards Actualizing the value potential of Korea health insurance review and assessment (HIRA) data as a resource for health research: strengths, limitations, applications, and strategies for optimal use of HIRA data. J Korean Med Sci 2017;32:718-28.

11. Cheol Seong S, Kim Y-Y, Khang Y-H, et al. Data resource profile: the National health information database of the National health insurance service in South Korea. Int J Epidemiol 2016;26:dyw253-800.

12. United Nations Statistics Division. International standard industrial classification of all economic activities (ISIC) revision 3.0, 1989. Available: https://unstats.un.org/unsd/publication/seriesm/seriesm 4rev3_1e.pdf [Accessed 7 Dec 2018]

13. National Health Insurance Service. National health insurance statistical Yearbook. 2015. (Korean version only). Available: http:// www.nhis.or.kr/menu/boardRetriveMenuSet.xx?menuld=F3321 [Accessed 7 Dec 2018].

14. McCullagh P, Nelder J. Generalized linear models: monographs on statistics and applied probability. Vol. 37. Chapman \& Hall, London 1989.

15. U.S. Bureau of labor statistics, U.S. department of labor. injuries, illnesses, and Fatalites. Available: https://www.bls.gov/iif/soii-chartdata-2017.htm [Accessed 21 Dec 2018].

16. Solomon C, Poole J, Palmer KT, et al. Non-Fatal occupational injuries in British agriculture. Occup Environ Med 2007;64:150-4.

17. Berriault CJ, Lightfoot NE, Seilkop SK, et al. Injury mortality in a cohort of mining, smelting, and refining workers in Ontario. Arch Environ Occup Health 2017;72:220-30.

18. Groves WA, Kecojevic VJ, Komljenovic D. Analysis of fatalities and injuries involving mining equipment. J Safety Res 2007;38:461-70.

19. Roberts SE. Occupational mortality in British commercial fishing, 1976-95. Occup Environ Med 2004;61:16-23.
20. Kool B, Ameratunga S, Scott N, et al. The epidemiology of workrelated injury admissions to hospitals in the Midland region of new Zealand. Injury 2017;48:2478-84.

21. Benavides FG, Benach J, Muntaner C, et al. Associations between temporary employment and occupational injury: what are the mechanisms? Occup Environ Med 2006;63:416-21.

22. Hayashi $\mathrm{S}$, Noda $\mathrm{T}$, Kubo $\mathrm{S}$, et al. Variation in fracture risk by season and weather: a comprehensive analysis across age and fracture site using a national database of health insurance claims in Japan. Bone 2018.

23. Riggs BL, Khosla S, Melton LJ. Sex steroids and the construction and conservation of the adult skeleton. Endocr Rev 2002;23:279-302.

24. Sullivan SD, Lehman A, Nathan NK, et al. Age of menopause and fracture risk in postmenopausal women randomized to calcium + vitamin $\mathrm{D}$, hormone therapy, or the combination: results from the women's health Initiative clinical trials. Menopause 2017;24:371-8

25. Cho Y, Park J, Ju B, et al. Women Leaders' Work-Life Imbalance in South Korean Companies: A Collaborative Qualitative Study. Human Resource Development Quarterly 2016;27:461-87.

26. Lim S-S, Yoon J-H, Rhie J, et al. The relationship between free press and under-reporting of non-fatal occupational injuries with data from representative national indicators, 2015: focusing on the lethality rate of occupational injuries among 39 countries. Int J Environ Res Public Health 2018;15:2856.

27. Nishikitani M, Yano E. Differences in the lethality of occupational accidents in OECD countries. Saf Sci 2008;46:1078-90.

28. Chiron M, Bernard M, Lafont S, et al. Tiring job and work related injury road crashes in the GAZEL cohort. Accident Analysis \& Prevention 2008;40:1096-104.

29. OECD. Hours worked (indicator) 2019 (accessed 04 Jun 2019).

30. Ministry of employment and labor. MOEL survey data: the labor force survey at establishments, 2015. Available: http://laborstat.moel.go. kr/ [Accessed 24 Dec 2018].

31. Tessier-Sherman B, Galusha D, Taiwo OA, et al. Further validation that claims data are a useful tool for epidemiologic research on hypertension. BMC Public Health 2013;13:51.

32. Vegso S, Cantley L, Slade M, et al. Extended work hours and risk of acute occupational injury: a case-crossover study of workers in manufacturing. Am J Ind Med 2007;50:597-603. 